\title{
INCIDENCE OF DELIRIUM IN ADULTS AFTER SEVOFLURANE; COMPARISON TO HALOTHANE. MODULATORY EFFECT OF MIDAZOLAM
}

\author{
By \\ Fahmy A. Fahmy*, and \\ Roshdy M. Al-Jamal ${ }^{\star \star}$
}

\begin{abstract}
From
Assistant Professor of Anesthesia-Mansoura University, Egypt Assistant Professor of Psychiatry - Mansoura University., Egypt
\end{abstract}

\begin{abstract}
Emergence of delirium after sevoflurane anesthesia has been mentioned by many investigators, yet almost in children(1). This study was conducted to elucidate and assess the severity and incidence of delirium in surgical adult patients scheduled for minor surgery under different anesthetic techniques. Also modulatory effect of midazolam was studied.
\end{abstract}

One hundred eighty, ASA I, II adult patients aged $17-48$ years who underwent minor to moderate surgery lasting less than one hour were randomly assigned to one of five equal groups each of 36 patients; (Group I) : $8 \%$ sevoflurane VIMA, (Group II) : Sevoflurane - Midazolam 2.5-5 mg IV 5 minutes pre-operatively, (Group III) : Sevoflurane 2, 4, 6, 8 increments, Group IV received propofol $2.5 \mathrm{mg}$ IV and maintenance with Sevoflurane, and Group $V$ which had halothane induction (1, 2, 3.5\%) and maintenance (1MAC). All patients received fentanyl 100 ug IV, 30 minutes pre-operatively and $50 \mathrm{mg}$ pethidine i.m. just before end of surgery. All patients were monitored as regards ECG, pulse oximetry and end tidal $\mathrm{CO} 2$. Maintenance by sevoflurane 1-1.5 MAC in N2O: $\mathrm{O} 2$ (50: $50 \%$ ) for all patients except group V, halothane. Ventilation was controlled in Groups III, IV and V. Any airway events during induction, maintenance and emergence were noted. Delirium was recorded. Patients who had agitation beyond $5 \mathrm{~min}$. were given midazolam 2.5 - $5 \mathrm{mg}$ i.v.

There were no significant differences among the five groups with respect to age, body weight and duration of anesthesia. All had $\mathrm{SaO}_{2}>96$. Ventilation was adequate in all groups $\left(\mathrm{PETCO}_{2}\right.$ range $30-36 \mathrm{mmHg}$ ). NoMANSOURA MEDICAL JOURNAL 
ticeably apnea was the prominent airway event being highest in Group II (83\%) and next GP I (67\%). Delirium occurred in 16 patients in Group I (44\%) next in Group III 14 (39\%), and least Group IV (5.6\%). Halothane (Group V) showed delirium incidence of $11 \%$. No seizure was seen in all patients. Delirium was highest and more severe in VIMA Group I (44\%) while least in propofol Group IV (5.6\%). Five out of total 48 delirious patients had severe form (three in Group I and two in Group III). Three of them responded well to midazolam and other two changed into mild agitation. Midazolam combination in group II decreased the severity of delirium.

To Conclude, Sevoflurane was found to be associated with highest incidence of delirium in VIMA group. Sevoflurane still had far incidence of delirium compared to halothane. Yet, none developed seizures. Midazolam attenuated the severity of delirium less affecting the frequency.

\section{INTRODUCTION}

Delirium is a complex neuropsychiatric syndrome that typically involves a plethora of cognitive and non-cognitive symptoms. Delirium is a disturbance of consciousness (usually acute) characterized by Vol. 34, No. 3 \& 4 July., \& Oct, 2003 clouding of consciousness, restlessness, confusion, psychomotor retardation, or agitation and affective lability,. It has a rapid onset and fluctuating waxing and waning course. It is common in patients presenting to general hospitals, emergency rooms, operation rooms and ICU. It is common also on association of drug intoxication or use of any stimulant or depressant drug if taken in sufficient amounts (1).

Postoperative delirium is a common phenomenon. However, this syndrome is often unrecognized and poorly understood. Health professionals must recognize delirium and patients at risk because delirium can lead to higher morbidity rates and longer lengths of hospital stay (2).

Delirium following Sevoflurane anesthesia has been mentioned by many investigators (3) who reported high incidence of excitement and he attributed that to early recovery and perception of pain. However, high incidence of delirium (40\%) was reported despite adequate postoperative analgesia (4).

Also, others have shown an incidence of $15 \%$ and $67 \%$ of postoperative agitation in unpremedicated children $(5$ and 6 respectively). 
Although most of the studies were conducted on children and the elderly who are more affected, a previous study (7) showed an incidence of $30 \%$ in adults. So, this study was conducted to elucidate and assess the severity and incidence of delirium in adults following sevoflurane under different anesthetic techniques. Also, the modulatory effect of midazolam was studied.

\section{PATIENTS AND METHODS}

This study was conducted prospectively over a period of 10 months at Royal Commission Medical Center (Saudia Arabia). After approval of local ethical committee and informed written consent, one hundred eighty adult patients of either sex (ASA I and II) who underwent minor to moderate surgery lasting less than one hour were enrolled in this study.

\section{Exclusion criteria :}

- Children and elderly

- Patients with pre-existing psychiatric disorders.

- Patients on psychotropic medications for the last 6 months.

- Some group of patients who were reported to be particularly at high risk of postoperative cognitive decline: those with low level of edu- cation; subjects with high preoperative levels of depressive symptomatology; and those with a recent history of cognitive impairment (8).

Patients were randomly allocated into 5 groups (each of 36 patients) as follows:

- Group I; induction (8\%) and maintenance by Sevoflurae, (GPI Sevo/ VIMA).

- Group II; same but patients received midazolam 2.5 - $5 \mathrm{mg} \mathrm{IV}, 5 \mathrm{~min}$. pre-induction (GP $\|$ Sev. MID.)

- Group III; induction 2, 4, 6, 8 increments of Sevoflurane, maintenance with Sevoflurane (GP Sevo INCR)

- Group IV; induction by propofol 2 $2.5 \mathrm{mg} / \mathrm{kg}-1$ and maintenance by Sevoflurane (Group IV-P-Sevo)

- Group V; halothane induction (1, 2, $3.5 \%$ ) and maintenance (1MAC).

-Ventilation was controlled in Gp. III, IV, $V$.

-Patients were monitored as regard ECG, pulse oximetry and end tidal $\mathrm{CO} 2\left(\mathrm{PETCO}_{2}\right)$.

-Patients with delirium were detected with the aid of the Confusion Assessment Method [CAM], (9). The severity of delirium in delerious patients was evaluated immeMANSOURA MEDICAL JOURNAL 
ditely after surgery using the MiniMental State Examination test [MMSE], (10).

Using the test Severity Scores of MMSE, patients with delirium were categorized into mild; 4-7, moderate; 8-12 and severe above 12. The frequency of different grades of severity among different groups were calculated using Chi Square test. The differences in delirium severity scores between different groups were statistically calculated using the ANOVA test. All statistical procedures were done using SPSS computer program.

Delirium diagnosis requires documentation of acute onset and fluctuant course during which patients may be uncommunicable. As a result, difficulties of detecting cognitive impairment with assessment tools like the Mini-Mental State Examination (MMSE) must be supplemented by application of DSM-IV or ICD-10 clinical criteria (11 and 12 respectively). The Confusion Assessment Method "CAM" is an operationalisation of key components of DSM that was used to detect delirium and the degree of severity was assessed by MMSE test.
Confusion Assessment Method [CAM]-(9).

Delirium was diagnosed if $(a)+(b)$ + one of either (c) or (d):

- Acute onset and fluctuating course :

Evidence of an acute change in mental status from the patient's baseline that changes in severity over the time.

- Inattention :

Patient has difficulty focusing attention, e.g. is easily distractible or has difficulty keeping track of conversation

- Disorganised thinking :

Patient's thinking is disorganised or incoherent, as evidenced by irrelevant conversation and unclear or illogical flow of ideas

- Altered consciousness :

A rating of a patient's level of consciousness other than alert (normal) i.e. vigilant or hyperalert, lethargic or drowsy, stuporous or comatose

\section{RESULTS}

There were no significant differences among the five groups with respect to age, body weight and duration of anesthesia (Table 1). All had $\mathrm{SaO}_{2}>96$. In groups I \& II, PET$\mathrm{CO}_{2}$ was in the range of $30-36$ $\mathrm{mmHg}$. Noticeably apnea was the

Vol. 34, No. 3 \& 4 July., \& Oct, 2003 
prominent airway event being highest in group II (83\%) and next GP । (67\%), Table 2.

Delirium occurred in 48 out of the total 180 patients. Table 2 and Fig. 1 show the incidence of delirium within each of the 5 groups. It was highest in Group I ( $n=16,44.4 \%$ ), followed by Group III ( $n=14,38.9 \%)$, then Group II $(n=12,33.3 \%)$, then Group V $(n=4$, $11.1 \%$ ) and it was least frequent in Group IV ( $n=2,5.6 \%$ ).

Table 3 and Fig. 2 show the distribution of patients with delirium ( $n=48$ ) among the 5 groups categorized by severity (as assessed by MMSE). Group I contained 5 mild (31.3\%), 8 moderate $(50 \%)$, and 3 severe cases (18.7\%). Group II had 8 mild $(66.7 \%)$, 4 moderate $(33.3 \%)$ and no severe cases. Group III contained 6 mild (42.9\%), 6 moderate $(42.9 \%)$, and 2 severe cases. Group IV contained only 2 mild cases ( $100 \%$ ) and group V had only 4 mild cases (100\%). The chi-square test did not show statistical significance $(p=0.206)$

Tables 4, $4 a$ and $4 b$ and Fig. 3 demonstrate the severity of delirium (as assessed by MMSE). Although the overall difference in severity between groups was not significant $(p=0.113)$ as shown In table $4 a$, the difference was found to be statistically significant when group I was compared to group II $(p=0.047)$, and also when group I was compared to group $V(p=0.032)$, table $4 b$.

VIMA technique was used and ventilation was spontaneous, delirium was least in group IV (5.6\%) where propofol was used for induction and ventilation was controlled. Five out of total 44 delirious patients had severe form (three in Group I and two in Group III). Three of them responded well to midazolam and other two changed into mild agitation. Midazolam combination in group II decreased severity of agitation. Vomiting was highest in Group I (10\%) and least in Group IV (2.8\%). 
Table 1: Patients' Characteristics

\begin{tabular}{llllll} 
& I Sevo-VIMA & II Sevo-Mid & $\begin{array}{c}\text { III Sevo- } \\
\text { Incr }\end{array}$ & IV P-Sevo & V- \\
\hline Patient (n) & 36 & 36 & 36 & 36 & 36 \\
Gender (M/F) & $14 / 12$ & $16 / 20$ & $20 / 16$ & $28 / 8$ & $18 / 18$ \\
Age ( $\boldsymbol{r}$ ) & $36(17-46)$ & $37(18-46)$ & $34(20-44)$ & $38(18-46)$ & $35(19-45)$ \\
Body weight (Kg.) & $72(7.8)$ & $71(7.7)$ & $71(7.9)$ & $72(7.7)$ & $71(7.8)$ \\
Duration of anest. (min.) & $46(35-54)$ & $45(37-55)$ & $48(40-55)$ & $46(42-50)$ & $45(35-55)$ \\
\hline
\end{tabular}

Sevo-VIMA - Sevoflurane - Volatile induction and maintenance of anesthesia.

Sevo-Mid - Sevoflurane - Midazolam

Sevo-Incr - Sevoflurane - Increments

P-Sevo - Propofol - Sevoflurane

Hal - Halothane

Table 2: Adverse Effects In Patients Under Different Sevoflurane Anesthetic Techniques.

\begin{tabular}{|c|c|c|c|c|c|}
\hline & $\begin{array}{c}\text { Sevo-VIMA } \\
N=36 \\
N(\%)\end{array}$ & $\begin{array}{c}\text { II Sero-Mid } \\
N=36 \\
N(\%)\end{array}$ & $\begin{array}{c}\text { III Sevo-Iner } \\
N=36 \\
N(\%)\end{array}$ & $\begin{array}{c}\text { IV P. Sevo } \\
M=36 \\
N(\%) \\
\end{array}$ & $\begin{array}{c}\text { V. Mal. } \\
\text { N=36 } \\
\text { N(\%) }\end{array}$ \\
\hline \multicolumn{6}{|l|}{ Arrangements: } \\
\hline \multicolumn{6}{|l|}{ a) Inductlon } \\
\hline Cough & $4(11 \%)$ & -. & $1(2.8 \%)$ & $\cdots$ & $*$ \\
\hline Apnea & $24(67 \%)$ & $30(83 \%)$ & $16(44 \%)$ & $4(11 \%)$ & $1(2.8 \%)$ \\
\hline \multicolumn{6}{|l|}{ b) Emergence } \\
\hline Leryngospasm & $2(6 \%)$ & $1(2.8 \%)$ & $2(6 \%)$ & $\cdots$ & - \\
\hline Yemiting & $10(28 \%)$ & $4(11 \%)$ & $6(17 \%)$ & 1 (2.8\%) & $3(8.4 \%)$ \\
\hline Delirlum & $16(4.4 \%)$ & $12(33.3 \%)$ & 14 (38.9\%) & $2(5.6 \%)$ & $4(11.1 \%)$ \\
\hline
\end{tabular}

Sevo-VIMA - Sevoflurane - Volatile Induction and maintenance of anesthesia.

Sevo-Mid - Sevoflurane - Midazolam

Sevo-Incr - Sevoflurane-Increments

P-Sevo - Propofol-Sevoflurane

Hal. - Halothane

Table 3: Distribution of Patients with Delirium in Different Severity

Grades

Among the Different Groups

\begin{tabular}{|c|c|c|c|c|c|c|c|c|}
\hline & & & \multicolumn{5}{|c|}{ GROUP } & \multirow[b]{2}{*}{ Total } \\
\hline & & & of & GII & Gili & Orv & OV & \\
\hline \multirow{3}{*}{$\begin{array}{l}\text { Dellitum } \\
\text { Severity } \\
\text { Grade }\end{array}$} & mाld & $\begin{array}{l}\text { Count } \\
\% \text { within GROU }\end{array}$ & $31.3 \%$ & $86.7 \%$ & $\begin{array}{r}6 \\
42.9 \%\end{array}$ & $\begin{array}{r}2 \\
100 \%\end{array}$ & $100 \%$ & $\begin{array}{r}25 \\
52.1 \%\end{array}$ \\
\hline & moderate & $\begin{array}{l}\text { Count } \\
\% \text { within GROU }\end{array}$ & & & $\begin{array}{r}6 \\
62 \%\end{array}$ & & & $\begin{array}{r}18 \\
37.5 \%\end{array}$ \\
\hline & severe & \% within GROU & \begin{tabular}{r|}
$50.0 \%$ \\
3 \\
$18.7 \%$
\end{tabular} & & $\begin{array}{r}2.07 \\
2.3 \%\end{array}$ & & & $\begin{array}{r}5 \\
10.4 \%\end{array}$ \\
\hline Total & - & $\begin{array}{l}\text { Count } \\
\% \text { within OROU }\end{array}$ & $\begin{array}{r}16 \\
100.0 \% \\
\end{array}$ & $\begin{array}{r}12 \\
100.0 \% \\
\end{array}$ & $\begin{array}{r}14 \\
100.0 \% \\
\end{array}$ & $\begin{array}{r}2 \\
100 \% \\
\end{array}$ & $100 \%$ & $\begin{array}{r}40 \\
100.0 \% \\
\end{array}$ \\
\hline
\end{tabular}

MMSE-Mini-Mental State Examination

$\mathrm{Cl}$ : - Sevollurane - Volatile Induction and maintenance of anesthesla.

CII: - Sevoflurane - Midazolam

CIII: - Sevolfurane - Increments

CIV - Propolol - Sevollurane

CV: - Halothan

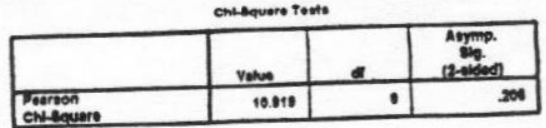

Vol. 34, No. 3 \& 4 July., \& Oct, 2003 
Fahmy A. Fahmy, and Roshdy M. Al-Jamal

Table 4: Severity Scores of Delirium as Assessed by MMSE in Different Groups

\begin{tabular}{|c|c|c|c|c|c|}
\hline & $\mathrm{N}$ & Mean & $\begin{array}{c}\text { std. } \\
\text { Doviation }\end{array}$ & Minimum & Maximum \\
\hline जा & 10 & 9.13 & 3.30 & 4 & 15 \\
\hline GII & 12 & 6.83 & 2.08 & 4 & 10 \\
\hline GIII & 14 & 8.14 & 3.42 & 4 & 15 \\
\hline GN & 2 & 6.00 & 1.41 & 5 & 7 \\
\hline OV & 4 & 5.50 & 1.20 & 4 & 7 \\
\hline Total & $-\quad 48$ & 7.83 & 3.06 & 4 & 15 \\
\hline
\end{tabular}

MMSE:Mini-Mental State Examination

Cl: - Sevollurane - Volatlle Induction and maintenance of anesthesia.

CII: - Sevollurane - Midazolam

CIII: - Sevolfurane - Increments

CIV - Propofol - Sevoflurane

CV: - Halothan

Table 4a: ANOVA Test Results Of Severity Scores of Delirium

\begin{tabular}{|l|r|r|r|r|r|}
\hline & $\begin{array}{r}\text { Sum of } \\
\text { Squares }\end{array}$ & of & \multicolumn{1}{|c|}{$\begin{array}{c}\text { Mean } \\
\text { Square }\end{array}$} & F & Sif. \\
\hline Berween & 68.536 & 4 & 17.134 & 1.991 & .113 \\
Groups & 370.131 & 43 & 8.808 & & \\
Within Groups & 438.687 & 47 & & & \\
Total & & & & \\
\hline
\end{tabular}

Table 4b: Multiple Comparisons of Delltilum Severity Scores

(by Muste) in Dirrerent Groups

Dópendent Varlable: score

LSO

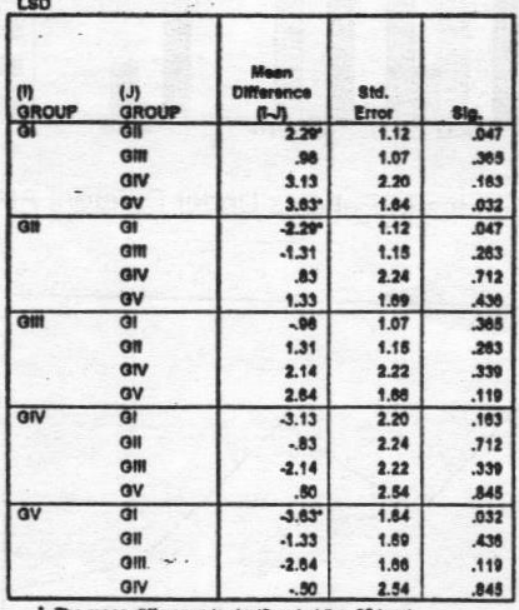

$\because$ The mean difference is significant at the .05 level.

MMSE-Mini-Mental Seate Examinarion

C: - Sevoffurane - Volatile induction and maintenance of aneschesis.

Cll: - Sevolurane - Midardem

Cll: - Sevolfurane - increments

$\mathrm{CN}$ - Mopolal-sevolurane

CV: - Halothan 


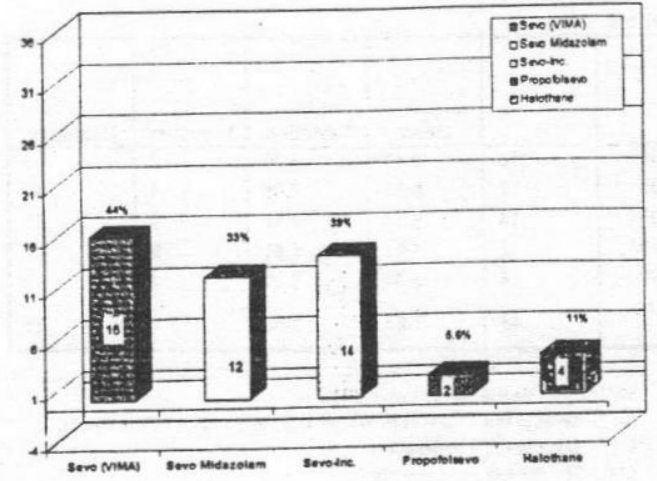

Fig. 1 : Incidence Of Delirium In Different Groups Of Patients Under Different Anesthetic Techniques

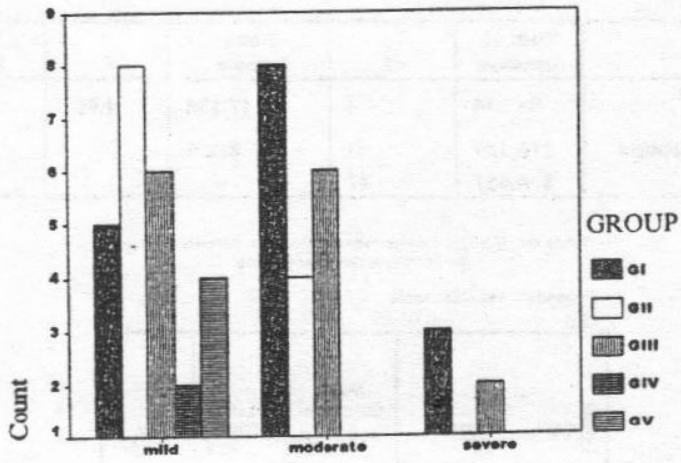

Fig. 2 : Delirium Severity Grades In Patients Under Different Anesthetic Techniques

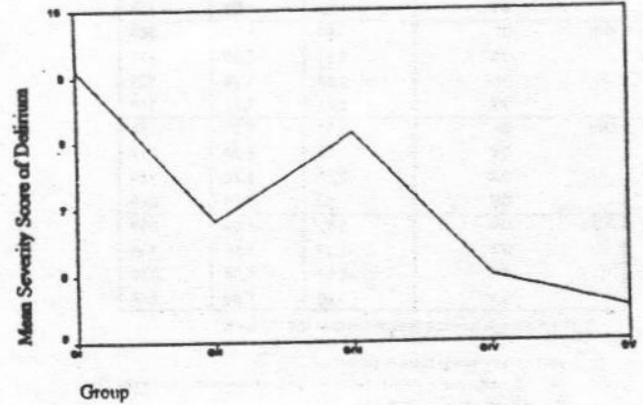

Fig. 3 : Mean Delirium Severity Score In Different Groups

Vol. 34, No. 3 \& 4 July., \& Oct, 2003 


\section{DISCUSSION}

Delirium refers to a state of impaired thinking, memory, perception and attention with inability to comprehend. Acute disturbances of global cognitive functioning are now recognised as 'delirium' in both The Diagnostic and Statistical Manual Of Mental Disorders "DSM-IV" and The International Classification of Diseases "ICD-10" (11 and 12 respectively).

Postanesthetic delirium is a type of postoperative emotional response occurring immediately after emergence from general anesthesia associated with excitement and confusion. The alternative terms "emergence delirium" or "postanesthetic excitement" are frequently used. Historically, the term postoperative psychosis is used interchangeably but more frequently refers to those conditions occurring after a lucid interval of 24 to 48 hours. Either phenomenon may arise from a variety of disturbances, with drug reactions, hypoxemia, or reaction to pain being common, or it may arise from psychological causes (13).

In our study, there was noticeable tendency of higher frequency of deliri- um in some groups; I, II and III over others; IV and $V$ although the differences were not statistically significant in terms of chi-square tests, (table 3). The reason might be the small number of patients in the latter groups; 2 and 4 respectively. However, this difference in the incidence of delirium among the various groups was more evident when the severity of delirium was compared where there was statistically significant difference between group I and each of II and V, (table 4b).

This may show that the emergent delirium might be related to the type of anaesthetic used and does not only result from pre-existing or predisposing risk factors. The study of the differential effects of various anaesthetic agents as well as the significance of the preoperative risk factors can hopefully - lead to better chances of avoiding postoperative delirium, and hence lessening the possible postoperative complications and duration of hospital stay.

Delirium and agitation following sevoflurane have been mentioned by many investigatcrs. Our study focused and highlighted the problem in adults as most studies in this field

MANSOURA MEDICAL JOURNAL 
were focusing on extremes of age based on higher susceptability of patients in these age groups. However, in a previous study there were reports of significant figures of incidence in adults. Thus, our present study focused and highlighted the problem in adults.

Highest incidence of delirium (44\%) was noticed in sevoflurane VIMA group where volatile induction and maintenance by sevoflurane was used. In this group, high sevoflurane (8\%) was used for induction as well as maintenance by the same agent. Next is sevoflurane increment group (39\%). Whether spontaneous or controlled ventilation chosen, the incidence of delirium was not significantly different in Group I vs. Group III, (table 2).

Halothane group compares favourably with Group III sevoflurane where patients had both induction and maintenance by the same anaesthetic and both groups had controlled ventilation. It is clear that delirium in halothane group is far less than that of sevoflurane group ( $11 \%$ vs. $39 \%$ )

Midazolam decreased more the severity rather than frequency and in some patients delirium is changed into mild agitation. Even sevoflurane sedation was found to be complicated by high incidence of intraoperative excitement (14). This evidently showed that sevoflurane is directly-somehowincriminated in producing agitation. Least incidence of agitation in our study was shown in the group IV where propofol was used for induction (5.6\%).

Also, higher incidence of agitation after sevoflurane (46\%) vs. propofol (9\%) was reported (15).

A same result was shown by Lopez, et al where higher incidence of agitation in sevoflurane group (15\%) vs. $(0 \%)$ in propofol. Propofol in our study lessened incidence from $44 \%$ to $5.6 \%$. So, it has a protective effect. Also propofol has a protective on favourable effect on incidence of vomiting where it is only $2.8 \%$ (one patient in Group IV). It is to note that no case of seizure has been recorded with Constant et al (16) who showed that sevoflurane increase EEG total spectral power and a shift towards the low frequency bands, also no seizure was recorded. Vakkuri et al (17) showed epileptiform EEG with sevoflurane induction in children and this was seen in $88 \%$ of children controlled ventilation (Hypocapnia may play a role). 
Constant et al. (16) pointed to a relative increase in sympathetic tone and marked inhibition of parasympathetic fibres. Parallel to this, Kulka, et al. (18) showed that clonidine prevents sevoflurane-induced agitation. This signifies the direct hemodynamic effect of sevoflurane.

The underlying molecular mechanisms of postoperative delirium is not fully understood. Serrotonin deficiency may be a cause as proposed by Uchida, et al (19).

Disruption or alteration in the serotonergic or dopaminergic pathways and transmission may be involved in the genesis of agitation (20).

A drug interaction in which sevoflurane is involved may be the cause of agitation. More elaborate research is needed.

\section{CONCLUSION:}

Sevoflurane VIMA is associated with highest incidence of delirium in adults compared to halothane. Yet, none developed seizures. Midazolam attenuates the severity of agitation and less affecting frequency.

The study of the differential effects of various anaesthetic agents as well as the significance of the preoperative risk factors can - hopefully - lead to better chances of avoiding postoperative delirium, and hence lessening the possible postoperative complications and duration of hospital stay.

\section{REFERENCES}

1. Binder, R (1988) : "organic mental disorders" in ""Review of General Psychiatry" Goldman $\mathrm{H}$, ed. Appleton and Lange. p 252-266.

2. Geary SM. Intensive care unit psychosis revisited (1994) : understanding and managing delirium in the critical care setting. Crit Care Nurs Q. 17(1):51-63.

3. Black, A., Sury, MRJ., Hemington, L., Howard, R., Mackersie, A., Hatch, DJ. (1996) : A comparison of the induction characteristics of Sevoflurane and Halothane in children. Anesthesia, 51: 539-542.

4. Aono, J., Ueda W., Mamiya, K., Takimoto, E., Manake, M. (1997): Greater incidence MANSOURA MEDICAL JOURNAL 
(1997) : Greater incidence of delirium during recovery from Sevoflurane anesthesia in preschool boys. Anesthesiology, 87: 12981300 .

5. Lopez, GM., Brimacombe, J., Clar, B. (1999) : Sevoflurane versus propofol for induction and maintenance of anesthesia with the laryngeal airway in children. Paeditr Anaesth. 9(6): 485-90.

6. Lapin, SL., Auden SM., Goldsmith LJ., Reynolds AM. (1999) : Effects of sevoflurane anaesthesia on recovery in children: a comparison with halothane. Pediatr Anaesth. 9(4): 299-304.

7. Fahmy, A (1998): Volatile induction and maintenance of anesthesia (VIMA) of sevoflurane. Induction and recovery characteristics. Banha Medical Journal, 15, 3: 545552 .

8. BONNEL, $F$ and CHEMINAL, J (2001) : Exposure to anaesthetic agents, cognitive functioning and depressive symptomatology in the elderly. The British Journal of Psychiatry, 178: 360-366.

9. Inouye, S. K., van Dyck, C. H., Alessi, C. A., et al (1990) : Clarifying confusion: the Confusion Assessment Method: a new method for detection of delirium. Annals Internal Medicine, 113: 941-948

10. Folstein, M. F., Folstein, S, Mchugn, P.R. (1975) : MiniMental State Examination. A practical method of grading cognitive state of patients for the clinician. J. Psyhiatry Res., 12: 189-198.

11. American Psychiatric Association (1994) : Diagnostic and Statistical Manual of Mental Disorders, ed 4. American Psychiatric Association, Washington, DC,

12. World Health Organization (1992) : The ICD-10 Classification of Mental and Behavioral Disorders: Clinical De- 
scriptions and Diagnostic

Guidelines. World Health

Organization, Geneva.

13. Olympio, MA (1991) : Postanesthetic delirium: historical perspectives. J Clin Anesth. 3(1):60-63.

14. Ibrahim, AE., Ghoneim, MM., Kharasch, ED., Epstein, RH., Groudine, SB., Elbert, JJ., Binstock, WB., Philip BK. (2001) : Speed of recovery and side-effects profile of sevoflurane sedation compared with Midazolam. Anesthesiology, 94(1): 8794.

15. Picard V., Dumont L., Pellegrini M. (2000) : Quality of recovery in children: sevoflurane versus propofol. Acta Anesthesiol-Scand. 44(3): 307-10.

16. Constant, I., Dubois, MC., Piat, V., Moutard, ML., McCue, M., Murat, I. (1991) : Changes in electro encephalogram and autonomic cardiovascular activity during induction of anesthesia with sevodlurane compared with halothane in children. Anesthesiology, 91 (6) : 1604-15.

17. Vakkuri, A., Yli-Hankala, A., Sarkela, M., Lindgren, L., Mennander, S., Korttila, K., Saarnivaara, L., Jantli, V. (2001) : Sevoflurane mask induction of anaesthesia is associated with epileptiform EEG in children. Acta Anaesthesiol. Scand. 45 (4): 805-1

18. Kulka, PJ., Bressem, M., Wieblack, A., Tryba, M. (2001) : Prevention of "Postsevoflurane delirium" with midazolam. Aneaethetist. 50(6): 401-5.

19. Uchida K., Aoki T., Ishizuka B (1999) : Post-operative delirium and plasma melatonin. Med. Hypotheses. 53(2): 103-6.

20. Stanford, BJ. and Stanford, SC. (1999) : Postoperative delirium indicating an adverse drug interaction involving the selective serotonin reuptake inhibitor, paroxetine? J. Psychopharmacol. 14(2): 186-5

MANSOURA MEDICAL JOURNAL 
